\title{
Psychometric validation of the Perceived Deficits Questionnaire-Depression (PDQ-D) instrument in US and UK respondents with major depressive disorder
}

This article was published in the following Dove Press journal:

Neuropsychiatric Disease and Treatment

\author{
Raymond W Lam' \\ François-Xavier Lamy ${ }^{2}$ \\ Natalya Danchenko² \\ Aaron Yarlas ${ }^{3}$ \\ Michelle K White ${ }^{3}$ \\ Benoît Rive ${ }^{2}$ \\ Delphine Saragoussi ${ }^{2}$ \\ 'Department of Psychiatry, University \\ of British Columbia, Vancouver, BC, \\ Canada; ${ }^{2}$ Global Outcomes Research, \\ Lundbeck SAS, Issy-les-Moulineaux, \\ France; ${ }^{3}$ Optum Patient Insights, \\ Optum, Inc., Lincoln, RI, USA
}

Correspondence: Raymond W Lam Department of Psychiatry, University of British Columbia, 2255 Wesbrook Mall, Vancouver, BC, V6T 2AI, Canada

$\mathrm{Tel}+\mathrm{I} 6048227325$

Fax +l 6048227922

Email r.lam@ubc.ca
Background: Although depression and cognitive dysfunction are connected, limited tools exist to capture the patient's perspective on cognitive dysfunction and its impact on major depressive disorder (MDD). We report results of a psychometric validation of the Perceived Deficits Questionnaire-Depression (PDQ-D), a self-report measure of cognitive dysfunction for use in MDD.

Methods: A non-interventional, prospective, panel-recruited, online survey was conducted using the PDQ-D in adults with and without MDD in the US and UK. Respondents were assessed at baseline and after 6 weeks (MDD only) (baseline: US $n=418$, UK $n=437,49 \%$ MDD; follow-up: US n=169, UK n=153, all MDD). The criterion measures included: Medical Outcomes Study Cognitive Functioning Scale-Revised-acute form (MOS COG-R), Patient Health Questionnaire-9 (PHQ-9), Patient Global Impression of Severity scale (PGI-Severity), Sheehan Disability Scale (SDS), Work Productivity and Activity Impairment Questionnaire: Specific-Health Problem (WPAI:SHP), and modified Lam Employment Absence and Productivity Scale (LEAPS). US and UK data were analyzed separately.

Results: Internal consistency was high for PDQ-D total scale and four subscales (Cronbach's alpha 0.81-0.96). Convergent validity was good, with strong concordance with MOS COG-R and moderate/small correlations with PHQ-9, SDS, WPAI:SHP, LEAPS, and PGI-Severity. Significant differences (all $P<0.001$ ) existed for all PDQ-D subscale and total scores between MDD/non-MDD samples. The PDQ-D was responsive to changes in depression symptom severity. Confirmatory factor analysis supported scoring of a global overall scale for perceived cognitive dysfunction.

Conclusion: The PDQ-D provides a reliable and valid measure of subjective cognitive dysfunction in patients with MDD.

Keywords: major depressive disorder, cognitive dysfunction, psychometric validation, self-report

\section{Introduction}

MDD is a common, chronic, and recurrent disorder characterized by one or more major depressive episodes. ${ }^{1}$ In 2010, the global point prevalence for MDD was estimated at $4.4 \%$ (close to 300 million cases). ${ }^{2}$ MDD was also a leading cause of disabilityadjusted life-years and the second leading cause of years lived with disability globally. ${ }^{3}$ Recent estimates of 12-month prevalence rates for MDD were 6.9\% in both Europe and the US. ${ }^{4,5}$ 
In addition to MDD having a significant negative impact on work, social relationships, and health-related quality of life, ${ }^{6}$ patients with MDD also exhibit a reduction in cognitive functioning domains, including attention, psychomotor speed, memory, and executive function, relative to healthy controls, ${ }^{7-9}$ and a relationship between MDD and cognitive impairment has been recognized for many years. ${ }^{10}$ Using the Central Nervous System Vital Signs assessment battery, evidence of cognitive dysfunction has been reported in $21 \%-31 \%$ of patients with depression compared with just $4 \%-5 \%$ of healthy controls. ${ }^{7,11}$ Furthermore, although not the only aspect of cognition, the DSM (fifth edition) diagnostic criteria for MDD include diminished concentration as a symptom of MDD. ${ }^{1}$ Deficits in several cognitive subscales have also been reported in patients with MDD, including executive function, ${ }^{9-12}$ mnemonic function, ${ }^{12}$ memory,,${ }^{9,10,13}$ attention, ${ }^{9,10}$ and processing speed. ${ }^{11}$ In a recent review of studies in adult patients aged $\leq 65$ years with MDD, McIntyre et al reported pronounced deficits ( $\geq 1 \mathrm{SD}$ below the normative mean) in executive function in $20 \%-30 \%$ of patients, ${ }^{14}$ and ability to concentrate was reported as a problem by $89.6 \%$ of patients with depression in the STAR*D study. ${ }^{15}$ In addition, ongoing persistent cognitive decline, specifically impairments in immediate memory and attention, has been reported in some patients with previous MDD, suggesting that MDD may have long-lasting effects on cognitive performance. ${ }^{8}$ Thus, the presence of cognitive dysfunction has broad implications for assessment, treatment and prognosis for psychosocial recovery in patients with MDD. ${ }^{16}$

Currently, there is no well-validated, widely accepted, patient-reported outcome instrument available to specifically assess cognitive dysfunction in patients with MDD. The PDQ ${ }^{17}$ was developed to measure patient-reported cognitive symptoms associated with MS and forms part of a series of generic and disease-specific instruments that comprise the Multiple Sclerosis Quality of Life Inventory. ${ }^{18}$ The PDQ has also been used for the assessment of cognitive symptoms in patients with a number of other conditions including MDD. ${ }^{19}$ Furthermore, a modified version of the PDQ, referred to as the PDQ-D, has been adapted for use by adults with MDD to measure cognitive dysfunction, specifically attention/ concentration, retrospective memory, prospective memory, and planning/organization. ${ }^{20}$

The current article reports the results of a prospective study designed to conduct a psychometric validation of the PDQ-D in adults with MDD in the US and in the UK. A key objective of this study was to provide a valid and practical tool for the measurement of cognitive dysfunction in adults with MDD that could be completed by patients in outpatient settings and would also be suitable for use in clinical trials and/or observational studies. The primary objective was to evaluate the reliability, acceptability, convergent and discriminant validity, responsiveness, and underlying factor structure of the PDQ-D when used to measure cognitive dysfunction in respondents with MDD. We hypothesized that the PDQ-D psychometric results would significantly differentiate between respondents with and without physician-diagnosed MDD, and according to MDD severity and evolution.

\section{Methods}

This was a non-interventional, prospective, epidemiological online survey conducted in the US and UK. In addition to the PDQ-D, the study included a number of other relevant patient-reported instruments for the purpose of assessing convergent validity and responsiveness. The study population included a sample of respondents with and without MDD, comprising men and women aged $\geq 18$ years (Figure 1 ). The survey questionnaires were administered in both samples at baseline and also at 6 weeks' follow-up in the MDD sample only.

\section{Respondents/sample}

US participants were recruited through the KnowledgePanel ${ }^{\circledR}$ maintained by GfK Custom Research, LLC, USA. UK participants were recruited through MrOps (London, UK; see Supplementary materials for further details). Both market research panels required consent from each member when joining, with the expectation that they would participate in surveys and their anonymized data could be used in publications. Each participant also signed an online consent form to participate in this study. Due to the nature of the study, which involved market research panels with informed consent, ethical approval was not required (for further information see Supplementary materials).

The medical history and demographic characteristics of the panel members were documented in advance of the study. In particular, all panel members reported their age, sex, previous diagnosis for depression, and whether they had been under a physician's care for depression in the 6 months before entry into the panel. Panel members were initially invited to participate in the study via an email invitation based on their pre-existing panel data. The follow-up survey was sent to all respondents with MDD who completed the baseline survey and were still available for study participation.

Male and female panel members aged $\geq 18$ years were eligible for inclusion in the general population sample if 


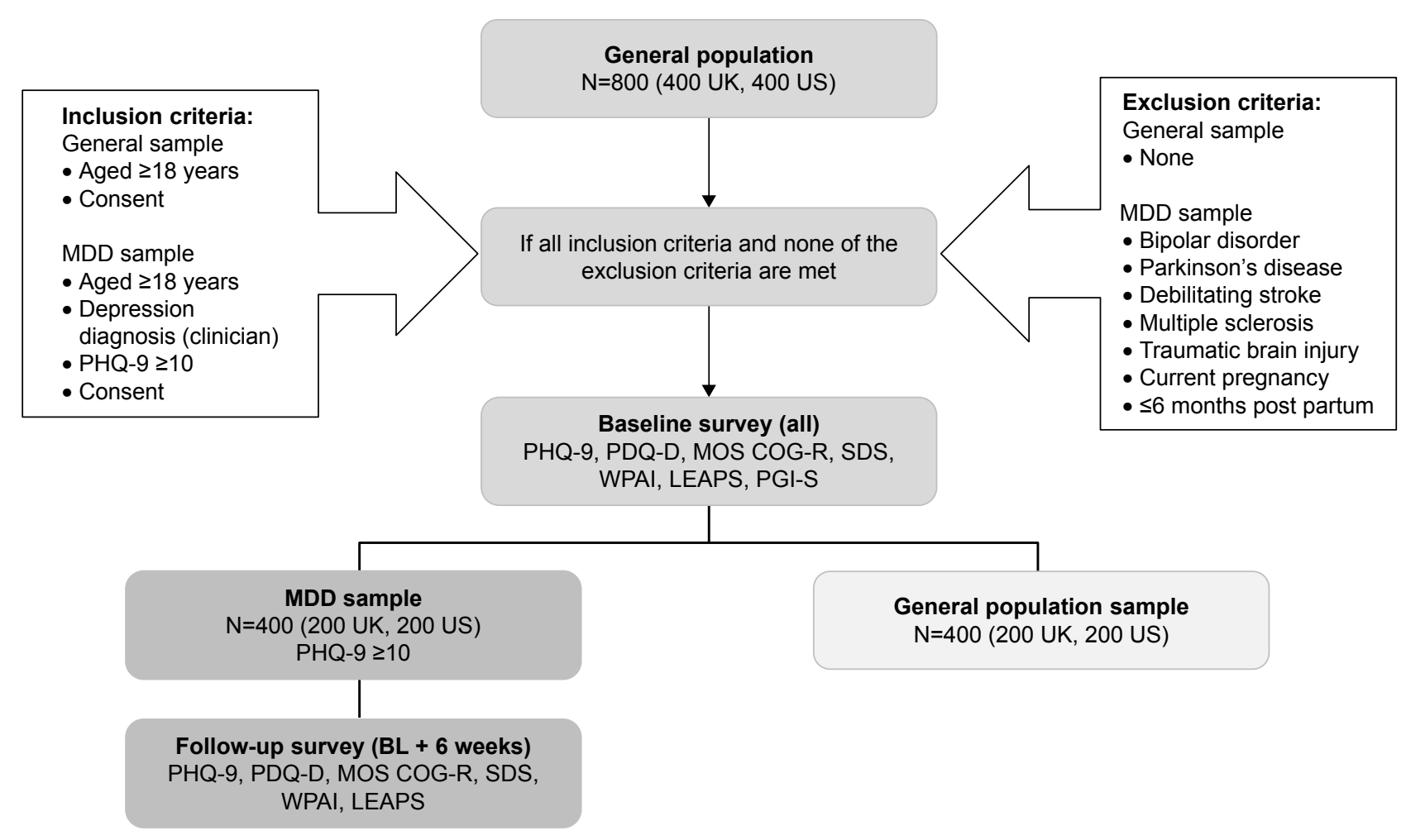

Figure I Study design and selection of participants, including initial target for number of respondents.

Abbreviations: BL, baseline; LEAPS, modified Lam Employment Absence and Productivity Scale; MDD, major depressive disorder; MOS COG-R, Medical Outcomes Study Cognitive Functioning Scale-Revised-acute form; PDQ-D, Perceived Deficits Questionnaire-Depression; PGI-S, Patient Global Impression of Severity scale; PHQ-9, Patient Health Questionnaire-9; SDS, Sheehan Disability Scale; WPAI, Work Productivity and Activity Impairment Questionnaire.

they provided informed consent to participate in the study and indicated that they were able to complete the designated surveys. On reaching the target number of respondents for the general population sample, those panel respondents who met the same criteria and, according to their pre-existing panel data, had reported being diagnosed with depression by a physician were randomly selected for potential inclusion in the MDD sample. Eligibility for inclusion in the MDD sample required evidence at screening of ongoing symptoms of depression as evaluated by the PHQ-9 (score $\geq 10$ ). ${ }^{21}$ Respondents were excluded from the study if they were pregnant or had given birth in the preceding 6 months, or if they had ever been diagnosed with bipolar disorder, Parkinson's disease, debilitating stroke, MS, or traumatic brain injury.

Throughout the study, respondents received the standard care provided by their physician; no specific treatment interventions were made in the context of the study.

\section{Measures}

The online survey comprised the PDQ-D and a series of other validated and established patient self-report instruments, which were used to assess cognitive functioning (MOS COG$\mathrm{R}){ }^{22,23}$ severity of depression (PHQ-921 and PGI-Severity [used at baseline] ${ }^{24}$ ) and work-related outcomes and social functioning (SDS, WPAI:SHP, and LEAPS ${ }^{25-28}$ ). Detailed descriptions of the criterion measures are provided in the Supplementary materials.

\section{Validation measure: PDQ-D}

The PDQ-D is a 20-item, patient-reported questionnaire with a 7-day recall period. Scores for four subscales of the PDQ-D (attention/concentration, retrospective memory, prospective memory, and planning/organization) are computed based on responses to five constituent items in each subscale. All 20 items use the same 5-point ordinal categorical response scale to reflect the frequency of experiencing a specific cognitive problem in the past 7 days. Scores for each of the four measured subscales are calculated by assigning a value of 0 ("never in the past 7 days"), 1 ("rarely - once or twice"), 2 ("sometimes - 3-5 times"), 3 ("often - about once a day"), or 4 ("very often - more than once a day") to each item, then summing the five items of that subscale, to produce a score ranging from 0 to 20 . A total global score for overall cognitive dysfunction (range $0-80$ ) is calculated by summing the four subscale scores. Higher scores for each subscale and for the total score indicate greater perceived cognitive dysfunction. 


\section{Data collection}

Data were collected using the self-administered online survey. Respondents in the MDD and general population samples completed the PHQ-9 at screening and the remaining survey questions at baseline. Only respondents in the MDD population were invited to complete the survey again at 6 weeks ( \pm 7 days) after baseline (Figure 1).

To prevent long delays in completing items in the survey, potential respondents were asked to complete the surveys online at their selected location within a 24-hour window. If a respondent failed to complete the baseline survey within 24 hours of starting, their data were excluded from the study analyses.

Before the study, the survey was pre-tested using 30 respondents each from the US and UK samples who met all MDD inclusion criteria and none of the exclusion criteria. The purpose of the pre-test was to confirm that the consent, screening, and survey content had been scripted correctly and to determine whether respondents had sufficient time to complete the survey. No problems or concerns were identified during pre-testing, so no changes were made to any study materials. Pre-test data were not included in the analysis, and pre-test respondents were not eligible for the main study sample.

To ensure that data collection was as consistent as possible in both the US and UK, only a single data-collection instrument was programmed for use with both samples, and both surveys were hosted by GfK Custom Research, LLC.

\section{Analyses}

It should be noted that the study was not an opinion poll survey where the objective is to extrapolate to a specific target population via weighting of observations. As a consequence, no weighting was applied to the patient observations.

Analyses conducted included assessment of internal consistency reliability, convergent validity, known-groups validity, responsiveness to change, and CFA. With the exception of the known-groups validity, responsiveness to change analyses, and the CFA, all analyses were conducted using baseline PDQ-D scores from the MDD samples only. With the exception of the CFA, all analyses were conducted separately for the US and UK samples. The CFA sample included respondents from both MDD and general population samples pooled across both countries.

Data were analyzed using Statistical Analysis Software (SAS ${ }^{\circledR}$; SAS Institute Inc., Cary, NC, USA) Version 9.2, Statistical Package for the Social Sciences (SPSS ${ }^{\circledR}$; SPSS Inc., Chicago, IL, USA) Version 17.0, or MPlus ${ }^{\circledR}$ (Muthén \& Muthén,
Los Angeles, CA, USA) Version 5. No missing-data imputation methods were used. Patient-reported instrument scores were only calculated for respondents who completed all constituent items.

Descriptive statistics, including median, mean, and SD of observed values and percentage of respondents with missing scores, were determined for each item, subscale, and the total score of the PDQ-D at baseline for the US and UK MDD samples. To determine any potential differences between sample populations, sex distributions of the US and UK MDD samples were compared using Fisher's exact test, and mean age and mean scores of all patient-reported measures were compared using independent-sample $t$-tests. The frequency of floor effects (frequency of respondents with the lowest possible score) and ceiling effects (frequency of respondents with the highest possible score) were also examined for the PDQ-D subscales and total score. Floor and ceiling effects for subscales and the total score were considered to be present if $>15 \%$ of respondents achieved the highest or lowest possible score. ${ }^{29}$

Internal consistency for each PDQ-D subscale and the total scale was estimated using Cronbach's alpha (with values $\geq 0.9$ considered excellent and $\geq 0.7$ considered acceptable) ) $^{30}$ and the average inter-item correlation (for most self-reported outcome tools this should be $\geq 0.3$ and preferably $>0.4$ for good reliability). ${ }^{31} \mathrm{~A}$ substantial increase in the internal consistency (Cronbach's alpha) of the parent subscale or total scale following removal of an item indicates that the item reduces the reliability of the scale.

Convergent validity was tested using Pearson's correlation coefficients to explore the direction and magnitude of associations between subscale and total scores of the PDQ-D and those of other patient-reported instruments (PHQ-9, SDS, WPAI:SHP, LEAPS, PGI-Severity, and MOS COG-R). A correlation coefficient with an absolute value of 0.5 indicates a large correlation, and coefficients with absolute values of 0.3 and 0.1 indicate moderate and small correlations, respectively. ${ }^{32}$ It was hypothesized that the strongest correlation would be between PDQ-D scores and scores from the cognitive functioning measure MOS COG-R, with this being a negative correlation as higher scores on the MOS COG-R indicate better functional outcomes (eg, less cognitive dysfunction). It was also hypothesized that PDQ-D scores would show moderate $(r \geq 0.3)$ positive correlations with scores from all other criterion measures, given that higher scores for each of these measures reflect worse functional outcomes (eg, more severe depression, greater impairment in functioning). 
Known-groups discriminant validity was tested by comparing the PDQ-D subscale and total scores between respondents in the MDD and general population samples at baseline. Within each country sample, PDQ-D scores in the two groups were compared using Cohen's $d$ effect size for differences between estimated means; ${ }^{32}$ an ANCOVA model was used for testing, with PDQ-D score sample as a fixed factor and subject age and sex as covariates. It was hypothesized that respondents with MDD would have higher (worse) PDQ-D scores compared with the general population.

Responsiveness to change in the MDD samples was evaluated by comparing changes in PDQ-D subscale and total scores with respondent scores on the PHQ-9. For this comparison, respondents in the US and UK MDD samples were categorized into three groups (worsened, no change, or improved) based on the magnitude of the difference between their baseline and 6-week follow-up scores on the PHQ-9 relative to the accepted minimal important change threshold for the PHQ-9 of 5 points. ${ }^{21}$ Change scores for each PDQ-D subscale and total score were calculated by subtracting each respondent's baseline score from his/her follow-up score. The "no change" group therefore included subjects whose PHQ-9 varied by $\leq 4$ points between baseline and follow-up. For both the US and UK MDD samples, ANCOVA models for each PDQ-D change score, with severity-change group as a fixed factor and respondent age and sex as covariates, were used to test for statistically significant differences in estimated mean PDQ-D change scores across categories. In models for which the omnibus (ie, global) effect of severity change reached statistical significance, post hoc analyses (with Bonferroni-adjusted $P$-values to control for inflated Type I error due to multiplicity) examined differences in estimated mean PDQ-D change scores for each pairwise comparison among severity-change groups. It was hypothesized that PDQ-D scores for respondents whose depression severity remained unchanged would be statistically significantly lower than for those whose depression severity worsened and statistically significantly higher than for those whose depression severity improved.

The factor structure of the PDQ-D was investigated using CFA. The proposed conceptual model that guided the development of the PDQ, from which the PDQ-D was modified, comprises four related but separable factors: attention/ concentration, retrospective memory, prospective memory, and planning/organization. However, a previous factor analysis of this instrument in a population of patients with MS supported a single-factor model. ${ }^{33}$ To test which, if either, of these structures best captured the observed interrelations among items in the PDQ-D, CFA was applied to baseline item scores of the total sample (ie, pooled across depressive status and country). The CFA models were tested using methods for categorical data (polychoric correlations) and the weighted least squares mean and variance adjustment estimator in the Mplus statistical modeling program..$^{34}$ The $\mathrm{CFI}^{35}$ and the RMSEA ${ }^{36}$ were used to assess the overall fit of the two models with the data. Adequate fit is indicated by a CFI value of $>0.95$ (range $0-1$ ) and an RMSEA value of $<0.08$ (range $0-1$ ). ${ }^{37}$ In case of a suboptimal fit for the four-factor and single-factor models, testing of a two-factor model, ${ }^{38,39}$ comprising four subscale factors with five items each plus a common factor with all 20 items loaded on it, was also planned.

\section{Results}

\section{Sample/respondents}

The first respondent was recruited to the study on November 28,2012 , and the last respondent completed the study on March 21, 2013.

The MDD sample comprised 421 respondents (US, $\mathrm{n}=206$; UK, $\mathrm{n}=215$ ) and the general population sample comprised 434 respondents (US, $n=212$; UK, $n=222$ ) (Figure 2). In the population with MDD, the proportion of female respondents was not statistically significantly different in the US and UK samples $(64.6 \%$ and $72.6 \%$, respectively; $P>0.05$ ); however, respondents in the US MDD sample were significantly older than those in the corresponding UK sample (mean age 50.8 vs 46.9 years, respectively; $P<0.01$ ). Comparison of the general population samples showed the opposite trend, with a significantly lower proportion of female respondents in the US vs UK populations ( $50.0 \%$ vs $75.2 \%$, respectively; $P<0.001)$ and no significant difference between the two countries for mean age (49.0 and 50.0 years, respectively; $P>0.05$ ). A total of 322 respondents with MDD (US, n=169; UK, n=153) entered the follow-up phase.

\section{Comparison of patient-reported instrument scores between US and UK MDD samples}

There was no evidence of a difference in the PHQ-9 total score and PGI-Severity score between the US and UK samples, suggesting comparable levels of depression severity and perception of overall health (Table 1). However, significant differences were observed for all other outcomes (PDQ-D, MOS COG-R, SDS, WPAI:SHP, and LEAPS) between 


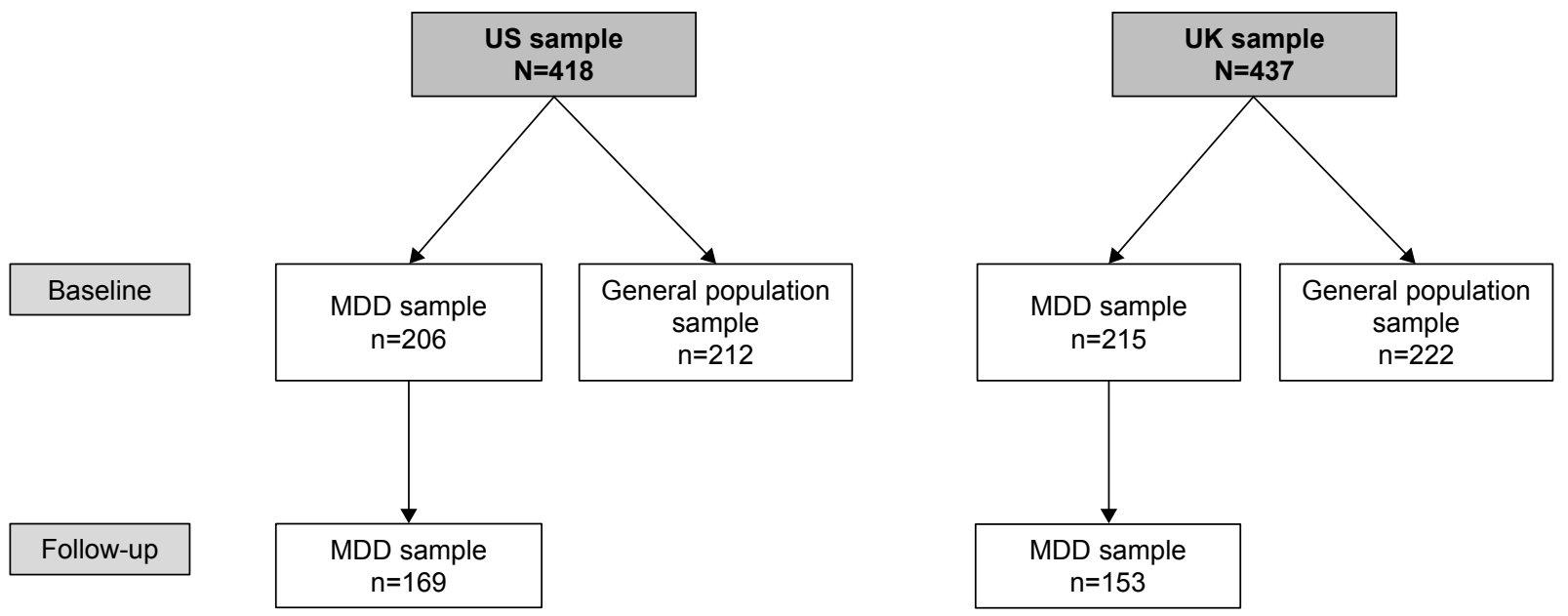

Figure 2 Subject disposition.

Abbreviation: MDD, major depressive disorder.

Table I Comparison of baseline demographic characteristics and baseline patient-reported scores for US and UK MDD samples

\begin{tabular}{|c|c|c|c|c|c|}
\hline \multirow[t]{2}{*}{ Characteristic } & \multicolumn{2}{|c|}{ US MDD (n=206) } & \multicolumn{2}{|c|}{ UK MDD (n=2I5) } & \multirow{2}{*}{$\begin{array}{l}\text { Difference } \\
\text { (US-UK) }\end{array}$} \\
\hline & $\mathbf{N}$ & Mean (SD) & $\mathbf{N}$ & Mean (SD) & \\
\hline Female sex $(\%)^{a}$ & 133 & 64.6 & 156 & 72.6 & -8.0 \\
\hline Age, years & 206 & $50.8(14.2)$ & 215 & $46.9(13.9)$ & 3.9 \\
\hline \multicolumn{6}{|l|}{ Educational status (\%) } \\
\hline Less than high school & 206 & 5.8 & - & - & - \\
\hline High school & 206 & 35.9 & - & - & - \\
\hline Some college & 206 & 30.6 & - & - & - \\
\hline Bachelor's degree or higher & 206 & 27.7 & - & - & - \\
\hline$\leq 5$ grade $\mathrm{C}$ GCSEs (or equivalent) & - & - & 215 & 29.8 & - \\
\hline$>5$ grade C GCSEs (or equivalent) & - & - & 215 & 9.3 & - \\
\hline Advanced school/college qualifications ${ }^{b}$ & - & - & 215 & 27.9 & - \\
\hline Undergraduate degree or equivalent & - & - & 215 & 13.5 & - \\
\hline Postgraduate degree or equivalent & - & - & 215 & 7.0 & - \\
\hline Professional qualification & - & - & 215 & 12.6 & - \\
\hline \multicolumn{6}{|l|}{ PDQ-D } \\
\hline Total score & 186 & $37.7(19.4)$ & 191 & $42.1(18.3)$ & -4.4 \\
\hline Attention/concentration & 198 & $10.6(5.3)$ & 208 & $11.7(4.8)$ & -1.2 \\
\hline Retrospective memory & 199 & $9.1(5.6)$ & 204 & $10.0(5.5)$ & -0.9 \\
\hline Prospective memory & 199 & $7.6(4.7)$ & 209 & $8.7(4.8)$ & -1.2 \\
\hline Planning/organization & 198 & $10.4(5.3)$ & 202 & II.4 (5.0) & -0.9 \\
\hline PHQ-9 Total score & 206 & 15.7 (4.9) & 215 & $16.6(5.0)$ & -0.9 \\
\hline MOS COG-R Total score & 205 & $35.0(12.6)$ & 215 & $31.5(12.4)$ & 3.5 \\
\hline SDS Total score & 206 & $16.0(8.1)$ & 215 & $18.7(7.7)$ & -2.8 \\
\hline \multicolumn{6}{|l|}{ WPAI:SHP score } \\
\hline Absenteeism & 92 & $5.7(14.4)$ & 77 & $9.2(20.7)$ & -3.5 \\
\hline Presenteeism & 91 & $33.7(26.0)$ & 75 & $49.3(21.1)$ & -15.6 \\
\hline Overall work impairment & 91 & $36.5(27.7)$ & 77 & $53.1(24.1)$ & -16.6 \\
\hline Activity impairment & 204 & $58.8(26.3)$ & 215 & $64.3(24.9)$ & -5.5 \\
\hline \multicolumn{6}{|l|}{ LEAPS Total score } \\
\hline Total score & 182 & $9.4(8.3)$ & 195 & $12.0(9.1)$ & -2.6 \\
\hline Productivity & 186 & $3.3(3.6)$ & 200 & $4.6(4.0)$ & -1.3 \\
\hline PGI-Severity score & 204 & $3.6(1.5)$ & 214 & $3.8(1.5)$ & -0.2 \\
\hline
\end{tabular}

Notes: apercentage of respondents is presented; 'Advanced or Advanced Subsidiary levels/Scottish Highers/National Vocational Qualification levels 3 and 4. "-" indicates not applicable.

Abbreviations: GCSE, General Certificate of Secondary Education; LEAPS, modified Lam Employment Absence and Productivity Scale; MDD, major depressive disorder; MOS COG-R, Medical Outcomes Study Cognitive Functioning Scale-Revised-acute form; PDQ-D, Perceived Deficits Questionnaire-Depression; PGI-Severity, Patient Global Impression of Severity scale; PHQ-9, Patient Health Questionnaire-9; SDS, Sheehan Disability Scale; WPAI:SHP, Work Productivity and Activity Impairment Questionnaire: Specific-Health Problem. 
the US and UK samples, suggesting greater cognitive and functioning impairment in respondents included in the UK sample.

\section{Item- and scale-level descriptive statistics}

Mean scores across all PDQ-D items were generally in the range of 2.5-3.5 for both the US and UK MDD samples, and SDs were generally between 1.2 and 1.4 for both MDD samples (Table 2). Floor and ceiling effects for the US and UK MDD samples were minimal for the PDQ-D total score and for each of the four subscales (Table 3), with values generally below $5 \%$.

There was a good level of acceptability of the PDQ-D in both the US and UK samples, with $90 \%$ and $89 \%$ of respondents, respectively, completing all 20 items. At the item level, the proportion of missing values varied between $0.5 \%$ and $2.4 \%$ in the US sample and between $0.0 \%$ and $1.9 \%$ in the UK sample (Table 2).

\section{Internal consistency reliability}

As shown in Table 3, Cronbach's alpha was $\geq 0.95$ for the PDQ-D total scores in the US and UK MDD samples, indicating excellent reliability; Cronbach's alpha was
$>0.80$ for each of the subscales for both samples, indicating good reliability. For both the US and UK MDD samples, the averages of the inter-item correlations within the total scale (both $\geq 0.50$ ) and within each of the four subscales (all $\geq 0.47$ ) also provide evidence of good internal consistency reliability (Table 3). Removal of most PDQ-D items in turn resulted in a reduction in Cronbach's alpha of each associated subscale in the US and UK MDD samples indicating appropriate reliability for each item. The reductions were $0.01-0.06$ and $0.01-0.07$ for the US and UK samples, respectively. Exceptions to this were an increase of 0.01 in the alpha coefficient in both the US and UK sample following removal of item 2 of the retrospective memory subscale, and no change in alpha coefficient in the US sample following removal of item 16 of the planning/ organization subscale.

\section{Convergent validity}

In both the US and UK populations, with the exception of the WPAI:SHP absenteeism subscale for which correlations with PDQ-D scores were close to zero, all correlations with criterion measures were in the hypothesized direction. PDQ-D baseline subscale and total scores correlated positively with

Table 2 Response frequency distributions and descriptive statistics for PDQ-D items at baseline

\begin{tabular}{|c|c|c|c|c|c|c|c|c|c|c|c|}
\hline \multirow[t]{3}{*}{ Subscale } & \multirow{3}{*}{$\begin{array}{l}\text { Item } \\
\text { no }\end{array}$} & \multicolumn{5}{|c|}{ US MDD sample } & \multicolumn{5}{|c|}{ UK MDD sample } \\
\hline & & \multirow[t]{2}{*}{$\mathbf{N}$} & \multirow[t]{2}{*}{$\begin{array}{l}\text { Missing } \\
\text { (\%) }\end{array}$} & \multirow{2}{*}{$\begin{array}{l}\text { Mean } \\
\text { score } \\
\text { (SD) }\end{array}$} & \multicolumn{2}{|c|}{$\begin{array}{l}\text { Percentage of } \\
\text { responders }\end{array}$} & \multirow[t]{2}{*}{$\mathbf{N}$} & \multirow[t]{2}{*}{$\begin{array}{l}\text { Missing } \\
(\%)\end{array}$} & \multirow[t]{2}{*}{$\begin{array}{l}\text { Mean } \\
\text { score (SD) }\end{array}$} & \multicolumn{2}{|c|}{$\begin{array}{l}\text { Percentage of } \\
\text { responders }\end{array}$} \\
\hline & & & & & “Never” & $\begin{array}{l}\text { "Very } \\
\text { often" }\end{array}$ & & & & “Never" & $\begin{array}{l}\text { "Very } \\
\text { often" }\end{array}$ \\
\hline \multirow{5}{*}{$\begin{array}{l}\text { Attention/ } \\
\text { concentration }\end{array}$} & I & 204 & 1.0 & 3.17 (1.29) & 9.7 & 21.5 & 215 & 0.0 & $3.36(1.25)$ & 6.3 & 25.7 \\
\hline & 5 & 202 & 1.9 & $3.06(1.32)$ & 14.5 & 18.3 & 215 & 0.0 & $3.4 I(1.21)$ & 7.9 & 22.5 \\
\hline & 9 & 202 & 1.9 & $3.05(1.32)$ & 15.6 & 17.2 & 213 & 0.9 & $3.39(1.22)$ & 7.3 & 22.5 \\
\hline & 13 & 205 & 0.5 & $3.62(1.26)$ & 8.1 & 32.3 & 212 & $\mathrm{I} .4$ & $3.98(1.11)$ & 2.6 & 44.0 \\
\hline & 17 & 205 & 0.5 & $2.63(\mathrm{I} .42)$ & 28.0 & 16.1 & 213 & 0.9 & $2.60(1.34)$ & 27.2 & 11.0 \\
\hline \multirow{5}{*}{$\begin{array}{l}\text { Retrospective } \\
\text { memory }\end{array}$} & 2 & 205 & 0.5 & $2.92(1.39)$ & 21.0 & 18.8 & 212 & 1.4 & $3.02(1.37)$ & 18.3 & 17.8 \\
\hline & 6 & 201 & 2.4 & $2.74(1.20)$ & 15.1 & 9.7 & 213 & 0.9 & $2.94(1.24)$ & 14.1 & 12.0 \\
\hline & 10 & 202 & 1.9 & 2.81 (I.39) & 22.0 & 16.1 & 214 & 0.5 & $3.14(1.35)$ & 16.2 & 19.9 \\
\hline & 14 & 203 & 1.5 & $2.70(1.43)$ & 28.5 & 17.2 & 211 & 1.9 & $2.81(1.42)$ & 26.2 & 16.2 \\
\hline & 18 & 205 & 0.5 & $3.05(1.34)$ & 14.0 & 19.9 & 213 & 0.9 & $3.14(1.28)$ & 11.5 & 18.3 \\
\hline \multirow{5}{*}{$\begin{array}{l}\text { Prospective } \\
\text { memory }\end{array}$} & 3 & 203 & 1.5 & $3.21(1.30)$ & 10.8 & 22.0 & 215 & 0.0 & $3.53(1.20)$ & 5.8 & 25.7 \\
\hline & 7 & 202 & 1.9 & $2.09(I .2 I)$ & 41.9 & 5.9 & 212 & 1.4 & $2.24(1.29)$ & 39.8 & 8.4 \\
\hline & 11 & 204 & 1.0 & $3.02(1.29)$ & 11.3 & 19.4 & 213 & 0.9 & $3.33(1.26)$ & 8.4 & 22.5 \\
\hline & 15 & 205 & 0.5 & $2.04(1.19)$ & 43.5 & 5.4 & 214 & 0.5 & $2.42(1.27)$ & 29.3 & 8.9 \\
\hline & 19 & 205 & 0.5 & $2.28(1.22)$ & 34.9 & 5.9 & 214 & 0.5 & $2.27(1.26)$ & 36.6 & 7.3 \\
\hline \multirow{5}{*}{$\begin{array}{l}\text { Planning/ } \\
\text { organization }\end{array}$} & 4 & 203 & 1.5 & $3.23(1.36)$ & 14.5 & 25.3 & 213 & 0.9 & $3.34(1.19)$ & 6.8 & 21.5 \\
\hline & 8 & 202 & 1.9 & $2.79(1.37)$ & 22.0 & 16.7 & 211 & 1.9 & $3.04(1.30)$ & 15.2 & 16.2 \\
\hline & 12 & 205 & 0.5 & $3.63(1.25)$ & 8.1 & 30.1 & 214 & 0.5 & $3.87(1.14)$ & 3.7 & 38.7 \\
\hline & 16 & 204 & 1.0 & $2.78(1.30)$ & 18.8 & 12.9 & 211 & 1.9 & $3.07(1.32)$ & 14.1 & 18.3 \\
\hline & 20 & 204 & 1.9 & $2.91(1.32)$ & 18.3 & 15.6 & 212 & 1.4 & $3.23(1.35)$ & 13.6 & 23.0 \\
\hline
\end{tabular}

Abbreviations: MDD, major depressive disorder; PDQ-D, Perceived Deficits Questionnaire-Depression. 
Table 3 Internal consistency reliability: PDQ-D scale-level properties at baseline for US and UK MDD samples

\begin{tabular}{l|l|l|l|l|l|l|l|l}
\hline Measure & $\mathbf{n}$ & Mean & Median & SD & $\begin{array}{l}\text { Floor } \\
\text { (\%) }\end{array}$ & $\begin{array}{l}\text { Ceiling } \\
\text { (\%) }\end{array}$ & $\begin{array}{l}\text { Cronbach's } \\
\text { alpha }\end{array}$ & $\begin{array}{l}\text { Average } \\
\text { inter-item } \\
\text { correlation }\end{array}$ \\
\hline US MDD sample & & & & & & & \\
(N=206) & 186 & 37.7 & 37.5 & 19.4 & 2.2 & 1.1 & 0.96 & 0.53 \\
Total score & 198 & 10.6 & 11.0 & 5.3 & 2.5 & 4.0 & 0.86 & 0.54 \\
Attention/concentration & 199 & 9.1 & 9.0 & 5.6 & 4.5 & 3.0 & 0.89 & 0.64 \\
Retrospective memory & 199 & 7.6 & 7.0 & 4.7 & 4.0 & 1.5 & 0.81 & 0.47 \\
Prospective memory & 198 & 10.4 & 10.5 & 5.3 & 3.0 & 3.0 & 0.86 & 0.56 \\
Planning/organization & & & & & & & \\
UK MDD sample & & & & & & & \\
(N=2I5) & 191 & 42.1 & 43.0 & 18.3 & 0.5 & 1.0 & 0.95 & 0.50 \\
Total score & 11.7 & 11.0 & 4.8 & 0.5 & 5.8 & 0.84 \\
Attention/concentration & 208 & 10.0 & 10.0 & 5.5 & 2.9 & 3.9 & 0.89 & 0.53 \\
Retrospective memory & 204 & 8.7 & 9.0 & 4.8 & 1.4 & 1.4 & 0.81 & 0.47 \\
Prospective memory & 209 & 11.4 & 11.5 & 5.0 & 0.5 & 6.4 & 0.84 \\
Planning/organization & 202 & & & & & 0.53 \\
\hline
\end{tabular}

Abbreviations: MDD, major depressive disorder; PDQ-D, Perceived Deficits Questionnaire-Depression.

scores from measures for which higher scores indicate worse outcomes (PHQ-9, SDS, WPAI:SHP, LEAPS, and PGISeverity) and correlated negatively with MOS COG-R for which a lower score indicates worse outcomes $(P<0.001$ for the magnitude of all correlations between PDQ-D scores and criterion measures being greater than 0 ) (Table 4).

As predicted, the strongest correlations were observed between the PDQ-D and the MOS COG-R. In the US sample,

Table 4 Convergent validity: Pearson correlation coefficients between baseline PDQ-D subscale and total scores and baseline scores from other survey measures in the US and UK study populations with MDD

\begin{tabular}{|c|c|c|c|c|c|c|}
\hline \multirow[t]{2}{*}{ Scale } & \multirow[t]{2}{*}{ Measure } & \multicolumn{5}{|c|}{ Pearson correlation at baseline } \\
\hline & & $\begin{array}{l}\text { PDQ-D } \\
\text { Total score }\end{array}$ & Attention & $\begin{array}{l}\text { Retrospective } \\
\text { memory }\end{array}$ & $\begin{array}{l}\text { Prospective } \\
\text { memory }\end{array}$ & Planning \\
\hline \multicolumn{7}{|l|}{ US MDD sample } \\
\hline PHQ-9 & Total score & 0.54 & $0.5 \mathrm{I}$ & 0.45 & 0.44 & 0.48 \\
\hline MOS COG-R & Total score & -0.78 & -0.72 & -0.69 & -0.70 & -0.71 \\
\hline SDS & Total score & 0.32 & 0.28 & 0.22 & 0.33 & 0.35 \\
\hline \multirow[t]{4}{*}{ WPAI:SHP } & Absenteeism & 0.06 & 0.04 & 0.00 & 0.04 & 0.08 \\
\hline & Presenteeism & 0.34 & 0.27 & 0.22 & 0.33 & 0.37 \\
\hline & Overall work impairment & 0.33 & 0.26 & 0.21 & 0.31 & 0.35 \\
\hline & Activity impairment & 0.32 & 0.28 & 0.23 & 0.32 & 0.34 \\
\hline \multirow[t]{2}{*}{ LEAPS } & Total score & 0.38 & 0.35 & 0.30 & 0.33 & 0.38 \\
\hline & Productivity & 0.37 & 0.33 & 0.29 & 0.33 & 0.35 \\
\hline PGI-Severity & Score & 0.31 & 0.28 & 0.20 & 0.26 & 0.37 \\
\hline \multicolumn{7}{|l|}{ UK MDD sample } \\
\hline PHQ-9 & Total score & 0.62 & 0.55 & 0.51 & 0.52 & 0.60 \\
\hline MOS COG-R & Total score & -0.80 & -0.76 & -0.69 & -0.71 & -0.74 \\
\hline SDS & Total score & 0.53 & 0.47 & 0.43 & 0.47 & 0.55 \\
\hline \multirow[t]{4}{*}{ WPAI:SHP } & Absenteeism & 0.05 & -0.01 & 0.10 & 0.07 & 0.03 \\
\hline & Presenteeism & 0.47 & 0.46 & 0.46 & 0.46 & 0.36 \\
\hline & Overall work impairment & 0.41 & 0.38 & 0.42 & 0.41 & 0.32 \\
\hline & Activity impairment & 0.53 & 0.47 & 0.44 & 0.43 & 0.59 \\
\hline \multirow[t]{2}{*}{ LEAPS } & Total score & 0.51 & 0.48 & 0.40 & 0.49 & 0.48 \\
\hline & Productivity & 0.52 & 0.46 & 0.41 & 0.49 & 0.49 \\
\hline PGI-Severity & Score & 0.43 & 0.39 & 0.34 & 0.30 & 0.48 \\
\hline
\end{tabular}

Abbreviations: LEAPS, modified Lam Employment Absence and Productivity Scale; MDD, major depressive disorder; MOS COG-R, Medical Outcomes Study Cognitive Functioning Scale-Revised-acute form; PDQ-D, Perceived Deficits Questionnaire-Depression; PGI-Severity, Patient Global Impression of Severity scale; PHQ-9, Patient Health Questionnaire-9; SDS, Sheehan Disability Scale; WPAI:SHP, Work Productivity and Activity Impairment Questionnaire: Specific-Health Problem. 
the Pearson correlation coefficient was -0.78 for PDQ-D total score and ranged from -0.69 to -0.72 for PDQ-D subscales; in the UK sample, the Pearson correlation coefficient was -0.80 for PDQ-D total score and ranged from -0.69 to -0.76 for PDQ-D subscales. Correlations between the PHQ-9 and the PDQ-D were generally moderate to large, with correlations for the PDQ-D total score approaching 0.60 , and correlations for the PDQ-D subscales ranging from 0.44 to 0.60 . Correlations with measures of depression severity (PGI-Severity), functioning and productivity (SDS, WPAI:SHP, and LEAPS) were generally small to moderate in the US sample (range $0.20-0.38$ ) and moderate to large in the UK sample (range 0.30-0.59).

\section{Known-groups validity}

For both US and UK study populations, statistically significant mean differences (all $P<0.001$ ) were observed for all PDQ-D subscale scores and the total score between the MDD samples and their corresponding general population samples (Figure 3). For both countries, mean PDQ-D total and subscale scores for respondents in the MDD group were at least twice as high (worse) than those in the general population, as indicated by effect-size estimates exceeding 1.0 for all scores (US sample, $\geq 1.28$; UK sample, $\geq 1.13$ [Table 5]), suggesting a large effect of MDD on each PDQ-D score.

\section{Responsiveness to change}

For the US sample, differences in mean changes from baseline in PDQ-D total scores and scores for all PDQ-D subscales were statistically significant as a function of their classification based on whether a respondent showed worsening, improvement, or no change from baseline in the severity of their depression based on the PHQ-9 minimal important change (all $P<0.01$ ) (Table 6). Further, post hoc pairwise comparisons between the three categories (worsened, no change, and improved) showed that respondents with meaningful improvements in depression severity from baseline to follow-up had statistically significantly greater improvements in all PDQ-D scores than respondents who experienced worsening or no change in PHQ-9 scores (all Bonferroni-adjusted $P<0.05$ for differences), with no statistical differences between the latter two groups for any PDQ-D scores.

In the UK sample, changes in mean scores for three of the PDQ-D subscales, although not for the Prospective-memory subscale or the PDQ-D total score, differed statistically significantly as a function of whether a respondent showed worsening, improvement, or no change in the severity of their depression ( $P<0.05$ for differences). For the three subscales with statistically significant omnibus differences, post hoc pairwise comparisons of change status showed that respondents with a meaningful improvement in depression severity from baseline to follow-up showed statistically significantly greater improvements than respondents with worsening of PHQ-9 scores during this period (all Bonferroni-adjusted $P<0.05$ for differences); however, scores for respondents with no change in depression severity did not differ significantly from those of respondents in either of the other two groups (Table 6).

\section{Factor analysis}

Fit indices for the one-factor model were poor, with both the CFI (0.878) and RMSEA (0.113) failing to meet the conventional thresholds established for these parameters. The subsequent CFA of the four-factor model, with the addition of some post hoc modifications (items 1 and 2 were allowed to correlate with item 3; item 10 was allowed to correlate with item 18 , and item 12 was regressed on the depression group [ie, MDD or general population]), provided a better fit, with the RMSEA at the conventional threshold for adequate fit (0.080); however, the CFI was just below the relevant threshold (0.938). The majority of items loaded most strongly on their hypothesized factor (the item's parent subscale): the only exceptions were for item 13 (an attention/ concentration item that loaded most strongly with planning/ organization items) and item 16 (a planning/organization item that loaded most strongly with attention/concentration items). For this model, the association among factors was strong, with all inter-factor correlations being $>0.85$ and the majority close to 0.95 , indicating that these factors were capturing either a single construct or at least very closely related constructs. Given the suboptimal fit of these models and the apparent relatedness of the four factors, the two-factor model was tested, while applying the same modifications as in the four-factor model. This two-factor model showed the best fit, with both RMSEA (0.073) and CFI (0.95) meeting or exceeding the conventional threshold values. The high loadings on the global factor relative to those on the specific subfactors strongly support scoring of the global scale. These factor analyses suggest that the global scale will have higher reliability and greater overall statistical power than the subscales in most analyses.

\section{Discussion}

This report describes results from a psychometric validation of the PDQ-D using an online survey of respondents with 

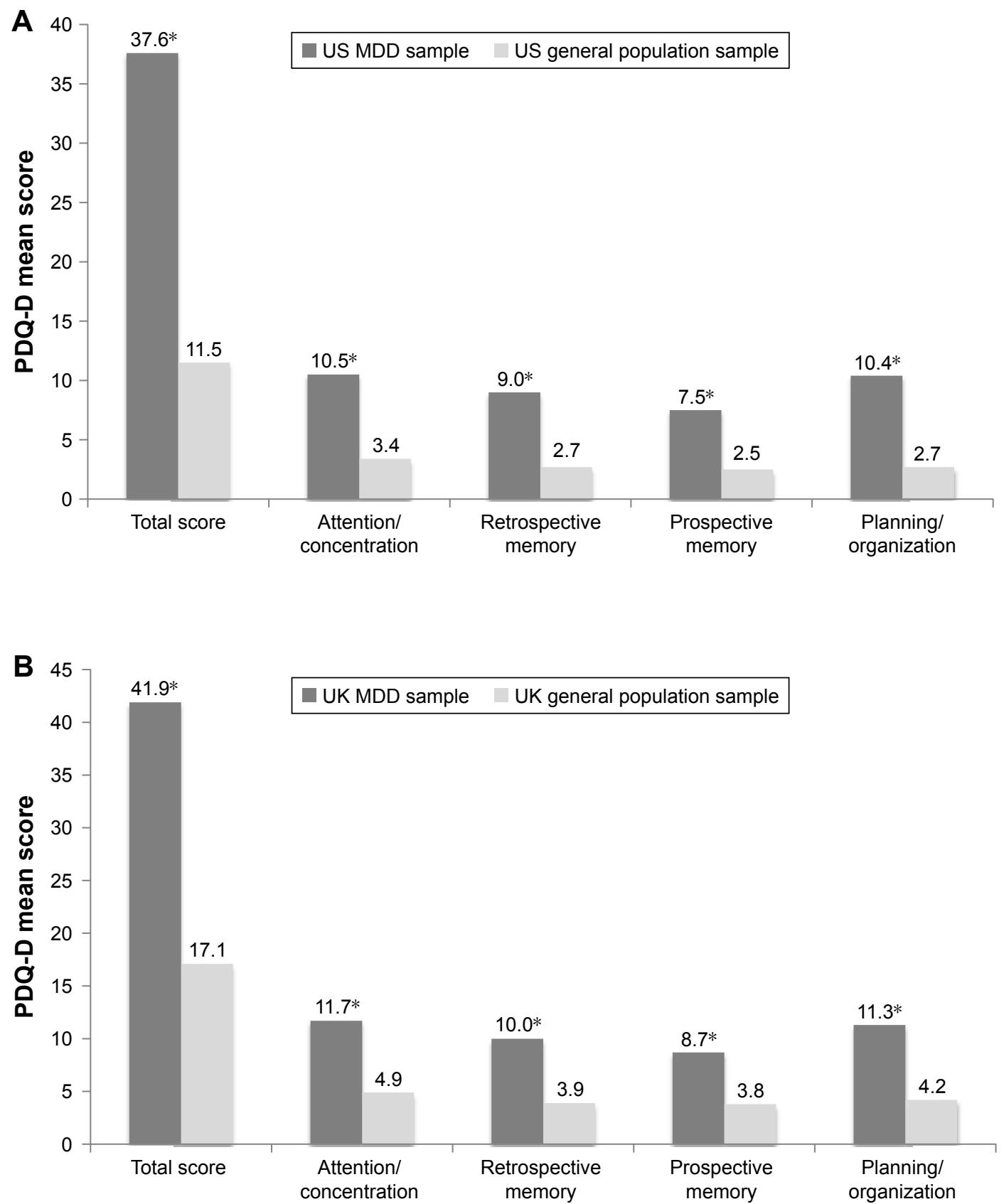

Figure 3 Known-groups validity: mean baseline PDQ-D subscale and total scores for the MDD and general populations: (A) US sample; (B) UK sample. $* P<0.00$ I vs general population sample.

Abbreviations: MDD, major depressive disorder; PDQ-D, Perceived Deficits Questionnaire-Depression.

and without MDD (defined as having received a diagnosis of depression by a physician and a PHQ- 9 score $\geq 10$ ) in the US and UK. The study was conducted in the US and the UK to allow elements of psychometric validation for the original English version of the PDQ-D to be assessed, and then tested in a US and EU setting. To our knowledge, this is one of only a small number of studies to validate a patient-reported instrument for the assessment of cognitive dysfunction in patients with depression. In recent years, both the Massachusetts General Hospital Cognitive and Physical Functioning Questionnaire and the British Columbia Cognitive Complaints Inventory have been validated in patients with depression, although not as extensively as the PDQ-D in the current study. ${ }^{40,41}$

The PDQ-D was adapted from the PDQ, a patientreported outcome measure of cognitive function that was 
Table 5 Mean comparison across MDD and general populations for testing known-groups validity of baseline PDQ-D total and subscale scores

\begin{tabular}{|c|c|c|c|c|c|c|c|c|}
\hline & \multicolumn{3}{|c|}{ MDD samples } & \multicolumn{3}{|c|}{ General population sample } & \multirow{2}{*}{$\begin{array}{l}\text { Mean } \\
\text { difference }\end{array}$} & \multirow[t]{2}{*}{$d^{a}$} \\
\hline & $\mathbf{N}$ & $\begin{array}{l}\text { Estimated } \\
\text { mean }\end{array}$ & SEM & $\mathbf{N}$ & $\begin{array}{l}\text { Estimated } \\
\text { mean }\end{array}$ & SEM & & \\
\hline \multicolumn{9}{|l|}{ US sample } \\
\hline Total score & 186 & 37.6 & 1.22 & 198 & 11.5 & 1.19 & 26.1 & 1.56 \\
\hline Attention/concentration & 198 & 10.5 & 0.34 & 203 & 3.4 & 0.33 & 7.1 & 1.50 \\
\hline Retrospective memory & 199 & 9.0 & 0.34 & 205 & 2.7 & 0.33 & 6.3 & 1.33 \\
\hline Prospective memory & 199 & 7.5 & 0.28 & 207 & 2.5 & 0.27 & 5.0 & 1.28 \\
\hline Planning/organization & 198 & 10.4 & 0.32 & 205 & 2.7 & 0.32 & 7.7 & 1.69 \\
\hline \multicolumn{9}{|l|}{ UK sample } \\
\hline Total score & 191 & 41.9 & 1.28 & 199 & I7. & 1.25 & 24.7 & 1.40 \\
\hline Attention/concentration & 208 & 11.7 & 0.33 & 209 & 4.9 & 0.32 & 6.8 & 1.44 \\
\hline Retrospective memory & 204 & 10.0 & 0.35 & 216 & 3.9 & 0.34 & 6.1 & 1.23 \\
\hline Prospective memory & 209 & 8.7 & 0.30 & 218 & 3.8 & 0.29 & 4.9 & 1.13 \\
\hline Planning/organization & 202 & 11.3 & 0.34 & 213 & 4.2 & 0.33 & 7.0 & 1.48 \\
\hline
\end{tabular}

Note: a Cohen's d effect size for differences among estimated means calculated from the ANCOVA model.

Abbreviations: ANCOVA, analysis of covariance; MDD, major depressive disorder; PDQ-D, Perceived Deficits Questionnaire-Depression; SEM, standard error of the mean.

originally developed for use in patients with MS. The PDQ was selected and adapted for use in MDD based on feedback and input from patients with MDD $(n=50)$ participating in focus groups and cognitive debriefing interviews. ${ }^{20}$ Similar to the PDQ, the PDQ-D comprises 20 items, but has a shorter recall period of 7 days (vs 4 weeks for the PDQ) and incorporates expanded response-category descriptions. ${ }^{20}$ Based on the results for the US and UK MDD populations, the current study findings indicate that the PDQ-D is a reliable and valid measure of cognitive dysfunction in patients with MDD.

In the present study, analysis of PDQ-D items in the MDD samples showed homogenous variance and no meaningful floor or ceiling effects for PDQ-D subscales or the total score of the PDQ-D for individual items.

High internal consistency reliability was established for the PDQ-D total scale and good internal consistency was found for the four proposed individual subscales (attention,

Table 6 Responsiveness to change: Comparison of mean changes from baseline in PDQ-D subscale and total scores for respondents with MDD as a function of their classification based on worsening, no change, or improvement from baseline to follow-up in PHQ-9 score

\begin{tabular}{|c|c|c|c|c|c|c|c|c|c|c|}
\hline \multirow[t]{2}{*}{ Measure } & \multicolumn{3}{|c|}{ Worsened $^{a}$} & \multicolumn{3}{|c|}{ No change ${ }^{a}$} & \multicolumn{3}{|c|}{ Improveda } & \multirow[t]{2}{*}{$P$-value ${ }^{b}$} \\
\hline & $\mathbf{n}$ & $\begin{array}{l}\text { Estimated } \\
\text { mean }\end{array}$ & SEM & $\mathbf{n}$ & $\begin{array}{l}\text { Estimated } \\
\text { mean }\end{array}$ & SEM & $\mathbf{n}$ & $\begin{array}{l}\text { Estimated } \\
\text { mean }\end{array}$ & SEM & \\
\hline \multicolumn{11}{|l|}{ US MDD sample } \\
\hline Total score & 15 & $1.6 *$ & 3.19 & 83 & $-2.7^{*}$ & 1.35 & 49 & $-10.5^{\#}$ & 1.76 & 0.0004 \\
\hline Attention/concentration & 16 & $0.6^{*}$ & 0.96 & 87 & $-0.8^{*}$ & 0.41 & 55 & $-2.5^{\#}$ & 0.51 & 0.0049 \\
\hline Retrospective memory & 17 & $0.4^{*}$ & 0.95 & 88 & $-0.7^{*}$ & 0.42 & 56 & $-2.6^{\#}$ & 0.52 & 0.0039 \\
\hline Prospective memory & 17 & $0.5^{*}$ & 0.75 & 87 & $-0.3^{*}$ & 0.33 & 56 & $-1.8^{\#}$ & 0.41 & 0.0045 \\
\hline Planning/organization & 16 & $0.4^{*}$ & 0.95 & 86 & $-1 . I^{*}$ & 0.41 & 56 & $-3.4^{\#}$ & 0.50 & 0.0001 \\
\hline \multicolumn{11}{|l|}{ UK MDD sample } \\
\hline Total score & 19 & -1.4 & 3.52 & 85 & -5.4 & 1.67 & 22 & -12.0 & 3.28 & 0.0798 \\
\hline Attention/concentration & 22 & $0.6^{*}$ & 0.91 & 99 & $-1.4^{*, \#}$ & 0.43 & 24 & $-3.1^{\#}$ & 0.87 & 0.0148 \\
\hline Retrospective memory & 23 & $0.3^{*}$ & 0.96 & 94 & $-1.5^{*, \#}$ & 0.47 & 23 & $-3.1^{\#}$ & 0.96 & 0.0499 \\
\hline Prospective memory & 23 & -0.7 & 0.85 & 97 & $-I .1$ & 0.41 & 24 & -2.2 & 0.83 & 0.3823 \\
\hline Planning/organization & 22 & $0.3^{*}$ & 0.94 & 94 & $-1.7^{*, \#}$ & 0.45 & 23 & $-3.7^{\#}$ & 0.92 & 0.0111 \\
\hline
\end{tabular}

Notes: *,\#Estimated means within a row with different superscripts $\left(*\right.$ or $\left.{ }^{*}\right)$ are significantly different $(P<0.05)$ based on post hoc paired comparison using Bonferroni's correction for multiple comparisons. a“'Improved" respondents' baseline PHQ-9 score exceeded follow-up score by $\geq 5$ points; “No change" respondents' PHQ-9 scores at baseline and follow-up were within 5 points of each other (in either direction); “Worsened" respondents' follow-up PHQ-9 score exceeded baseline score by $\geq 5$ points. 'Difference in estimated mean PDQ-D scores across PHQ-9 categories.

Abbreviations: MDD, major depressive disorder; PDQ-D, Perceived Deficits Questionnaire-Depression; PHQ-9, Patient Health Questionnaire-9; SEM, standard error of the mean. 
retrospective memory, prospective memory, and planning). Notably, the vast majority of PDQ-D items contributed positively to the internal consistency reliability of the PDQ-D subscales, and no items had a meaningful negative impact on the internal consistency reliability of the PDQ-D subscales.

The PDQ-D demonstrated good convergent validity, as indicated by strong concordance with an existing, validated measure of cognitive dysfunction (MOS COG-R) and generally moderate to small correlations with measures of constructs known to be associated with cognitive difficulties (PHQ-9, SDS, WPAI:SHP, LEAPS, and PGI-Severity); the strong correlation with the MOS COG-R and smaller correlations with other measures confirm that cognitive dysfunction is a concept different from that captured by these latter instruments. This observation was expected, given that both instruments were developed to measure the same underlying construct, namely cognitive dysfunction. The PDQ-D and MOS COG-R each have their own advantages and disadvantages. Specifically, the inclusion of a greater number of items in the PDQ-D (20 vs 6 items for MOS COG-R) affords the PDQ-D greater precision. ${ }^{20}$ Also, the facility to determine PDQ-D subscale scores (not possible with the MOS COG-R), in addition to a total score, allows assessment of impairments specific to particular aspects of cognitive functioning. In contrast, the MOS COG-R is normative based, and the inclusion of fewer items means that it is associated with less patient burden connected with completing the assessment. ${ }^{23}$

In terms of discriminant validity, the PDQ-D performed well. Large differences in scores were observed between the MDD samples and the general population samples, with the MDD groups scoring approximately 2-3 times higher (ie, worse) than the general population groups.

The PDQ-D also demonstrated responsiveness to changes in depression severity in respondents with MDD who showed a clinically significant decrease in their PHQ-9 score over a 6-week period. The PHQ-9 scale was selected for the responsiveness analysis as it is one of very few patient-reported outcome measures frequently used to assess depression severity. By using the PHQ-9 as the responsiveness criterion we were able to show a correlation between improvement in depression and reduction in cognitive dysfunction.

Validation of the PDQ-D independently in both US and UK populations provides further support for the scale. It should be noted that the US and UK samples (MDD and general population) differed in terms of demographic characteristics, specifically age and sex, with respondents in the US MDD sample being significantly older than those in the UK MDD sample and the US general population containing a significantly lower proportion of female respondents than the UK sample. These differences in age and sex distribution between the US and UK populations, although not large in practical terms, were unexpected and further examination of the study populations should be considered to determine whether the differences are a function of differential recruiting/sampling techniques or whether they reflect true differences. Health outcomes (PHQ-9 and PGI-Severity) were similar in the US and UK MDD samples, indicating similar levels of depression severity and perception of overall health; however, the US MDD sample reported less cognitive dysfunction and less impairment in work and activities compared with the UK sample. This difference was possibly attributable to a reporting bias as it is unlikely that depression would have a differential impact on these outcomes as a function of country; however, differences related to cultural aspects or health care system specificities cannot be excluded. Assuming that the relation between depression and objective cognitive dysfunction (eg, performance measured as part of a cognitive test battery) would be similar, there appears to be a tendency for the US MDD population to underestimate cognitive dysfunction, the UK MDD population to overestimate cognitive dysfunction, or a combination of both. This bias may not be limited to an MDD population and supports our approach of conducting separate analyses for each country.

CFA supported the scoring of a global overall scale for cognitive dysfunction rather than the four subscales of cognitive functioning. Although further study of the factor structure is needed, the results support greater confidence in the total score being predictive of overall cognitive dysfunction in MDD than in the subscale scores being predictive of specific aspects of cognitive dysfunction. In addition, our findings support the National Multiple Sclerosis recommendation that 'caution should be exercised when interpreting PDQ subscale scores'. ${ }^{18}$

\section{Limitations}

This psychometric validation study has some limitations. First, a diagnostic interview was not conducted to confirm the diagnosis of MDD in respondents. Inclusion in the MDD sample was based on respondent self-report of a depression diagnosis by a physician and current symptoms meeting the PHQ-9 threshold. The PHQ-9 criterion used (score $\geq 10$ ), however, has been shown in previous studies to have both sensitivity and specificity of $88 \%$ for the DSM 
(fourth edition) ${ }^{42}$ diagnosis of MDD (positive predictive value of $31 \%$ and $51 \%$ for PHQ-9 cutoff of 9 and 15 , respectively), ${ }^{21}$ making it a reasonable proxy for an MDD diagnosis. A second limitation of the study is that the analyses took a very conservative approach to imputation of missing item scores for the PDQ-D, resulting in missing scale scores for a number of respondents, particularly for the total scale. However, the frequency of missing values was very low, indicative of good acceptability, with less than $2.4 \%$ of missing values per item and around $10 \%$ of missing total scores. For future studies, imputation approaches could be considered to reduce the number of missing scale scores, and the current analyses repeated to determine whether the same conclusions could be made. Finally, it is important to note that as an assessment tool for "perceived" cognitive dysfunction, the PDQ-D measures different outcomes to objective neuropsychological testing. Consistent with this, Lovera et $\mathrm{al}^{43}$ reported a lack of correlation between the PDQ and objective cognitive tests in patients with MS. Further research is required on the assessment of perceived cognitive dysfunction in routine clinical practice. Regarding the need for cultural adaptation for worldwide use, a Korean and a Chinese version of the PDQ-D, incorporating only minor differences compared with English version, have been developed and recently validated. ${ }^{44,45}$

\section{Conclusion}

Our study findings have shown that the PDQ-D has a good structure, internal consistency, convergent validity, discriminant validity, and responsiveness, and provides a reliable and valid measure of subjective cognitive dysfunction in patients with MDD. Neuropsychological tests can provide detailed assessment of cognitive performance but are not feasible for routine clinical use. ${ }^{46}$ Patient-reported outcome measures can supplement the information from objective tests, and we believe that the PDQ-D will provide a practical tool for the assessment of cognitive dysfunction in adults with MDD in routine clinical practice to ensure that cognitive symptoms improve and remit with treatment alongside other depressive symptoms. Further research will be required to investigate the relationship between a comprehensive patient-reported outcome measure, such as the PDQ-D, and objective neuropsychological test performance.

\section{Abbreviations}

ANCOVA, analysis of covariance; CFA, confirmatory factor analysis; CFI, comparative fit index; DSM, Diagnostic and Statistical Manual of Mental Disorders; LEAPS, modified Lam Employment Absence and Productivity Scale; MDD, major depressive disorder; MOS COG-R, Medical Outcomes
Study Cognitive Functioning Scale-Revised-acute form; MS, multiple sclerosis; PDQ, Perceived Deficits Questionnaire; PDQ-D, Perceived Deficits Questionnaire-Depression; PGISeverity, Patient Global Impression of Severity scale; PHQ-9, Patient Health Questionnaire-9; RMSEA, root mean square error of approximation; SDS, Sheehan Disability Scale; STAR*D, Sequenced Treatment Alternatives to Relieve Depression; WPAI:SHP, Work Productivity and Activity Impairment Questionnaire: Specific-Health Problem.

\section{Ethics approval and consent to participate}

All patients enrolled in the study provided written informed consent. Due to the nature of the study, which involved market research panels with informed consent, ethical approval was not required (for further information see Supplementary materials).

\section{Acknowledgments}

The authors thank Jakob Bjorner, MD, PhD, of Optum, Inc., who assisted with some of the data analyses and interpretation (particularly the CFA). Editorial assistance was provided by Julie Adkins of Anthemis Consulting Ltd and funded by Lundbeck SAS. The study and editorial assistance in preparing the paper were funded by Lundbeck SAS. Lundbeck personnel were involved in the study design, in the collection, analysis, and interpretation of data, in the writing of the report, and in the decision to submit the article for publication. Preliminary results were presented at the 16th Annual European Congress of the International Society for Pharmacoeconomics and Outcomes Research (ISPOR) as a poster presentation. November 2-6, 2013 Dublin, Ireland. The poster's abstract was published in "Poster Abstracts" in Value in Health (Value in Health 2013;16:A330).

\section{Disclosure}

RWL has received speaker honoraria from the Canadian Network for Mood and Anxiety Treatments, the Canadian Psychiatric Association, Hansoh, Lundbeck, the Lundbeck Institute, and Pfizer; has received research funding from BC Leading Edge Foundation, Brain Canada, the Canadian Institutes of Health Research, the Canadian Network for Mood and Anxiety Treatments, Janssen, Lundbeck, the Movember Foundation, Pfizer, St. Jude Medical, University Health Network Foundation, and the VGH Foundation; and has served on consulting/advisory boards for Akili, Allergan, the Asia-Pacific Economic Cooperation, the Canadian Depression Research and Intervention Network, the Canadian 
Network for Mood and Anxiety Treatments, CME Institute, Janssen, Lundbeck, Medscape, Otsuka and Pfizer. FXL, DS, $\mathrm{BR}$, and ND were full-time employees of Lundbeck at the time of the study. AY and MKW are full-time employees of Optum, Inc., which received funding from Lundbeck to design the study and analyze the data; however, no financial payment was provided for their involvement in the development of the manuscript. The authors report no other conflicts of interest in this work.

\section{References}

1. American Psychiatric Association. Diagnostic and Statistical Manual of Mental Disorders. 5th ed. Arlington, VA: American Psychiatric Publishing; 2013.

2. Ferrari AJ, Charlson FJ, Norman RE, et al. The epidemiological modelling of major depressive disorder: application for the Global Burden of Disease Study 2010. PLoS One. 2013;8(7):e69637.

3. Ferrari AJ, Charlson FJ, Norman RE, et al. Burden of depressive disorders by country, sex, age, and year: findings from the global burden of disease study 2010. PLoS Med. 2013;10(11):e1001547.

4. Wittchen HU, Jacobi F, Rehm J, et al. The size and burden of mental disorders and other disorders of the brain in Europe 2010. Eur Neuropsychopharmacol. 2011;21(9):655-679.

5. Substance Abuse and Mental Health Services Administration. Results from the 2012 National Survey on Drug Use and Health: Mental Health Findings. NSDUH Series H-47, HHS. Publication No. (SMA) 13-4805. Rockville, MD: Substance Abuse and Mental Health Services Administration; 2013. Available from: www.samhsa.gov/data/sites/default/ files/NSDUHmhfr2012/NSDUHmhfr2012.pdf. Accessed September 27, 2018.

6. Kessler RC. The costs of depression. Psychiatr Clin North Am. 2012; 35(1):1-14.

7. Iverson GL, Brooks BL, Young AH. Identifying neurocognitive impairment in depression using computerized testing. Appl Neuropsychol. 2009;16(4):254-261.

8. Baune BT, Miller R, McAfoose J, Johnson M, Quirk F, Mitchell D. The role of cognitive impairment in general functioning in major depression. Psychiatry Res. 2010;176(2-3):183-189.

9. Rock PL, Roiser JP, Riedel WJ, Blackwell AD. Cognitive impairment in depression: a systematic review and meta-analysis. Psychol Med. 2014;44(10):2029-2040.

10. Hammar A, Ardal G. Cognitive functioning in major depression - a summary. Front Hum Neurosci. 2009;3:26.

11. Gualtieri CT, Johnson LG, Benedict KB. Neurocognition in depression: patients on and off medication versus healthy comparison subjects. J Neuropsychiatry Clin Neurosci. 2006;18(2):217-225.

12. Austin MP, Mitchell P, Goodwin GM. Cognitive deficits in depression: possible implications for functional neuropathology. Br J Psychiatry. 2001;178:200-206.

13. Sachs-Ericsson N, Joiner T, Blazer DG. The influence of lifetime depression on self-reported memory and cognitive problems: results from the National Comorbidity Survey-Replication. Aging Ment Health. 2008;12(2):183-192.

14. McIntyre RS, Cha DS, Soczynska JK, et al. Cognitive deficits and functional outcomes in major depressive disorder: determinants, substrates, and treatment interventions. Depress Anxiety. 2013;30(6):515-527.

15. Hollon SD, Shelton RC, Wisniewski S, et al. Presenting characteristics of depressed outpatients as a function of recurrence: preliminary findings from the STAR*D clinical trial. J Psychiatr Res. 2006;40(1): $59-69$.

16. Gonda X, Pompili M, Serafini G, et al. The role of cognitive dysfunction in the symptoms and remission from depression. Ann Gen Psychiatry. $2015 ; 14: 27$.
17. Sullivan JJ, Edgley K, Dehoux E. A survey of multiple sclerosis. Part 1. Perceived cognitive problems and compensatory strategy use. Can $J$ Rehabil. 1990;4:99-105.

18. National Multiple Sclerosis Society. The Consortium of Multiple Sclerosis Centers Health Services Research Subcommittee. Multiple Sclerosis Quality of Life Inventory: a User's Manual. New York, NY: The National Multiple Sclerosis Society; 1997.

19. Lawrence C, Roy A, Harikrishnan V, Yu S, Dabbous O. Association between severity of depression and self-perceived cognitive difficulties among full-time employees. Prim Care Companion CNS Disord. $2013 ; 15(3)$

20. Fehnel SE, Forsyth BH, Dibenedetti DB, Danchenko N, François C, Brevig T. Patient-centered assessment of cognitive symptoms of depression. CNS Spectr. 2016;21(1):43-52.

21. Kroenke K, Spitzer RL, Williams JB. The PHQ-9: validity of a brief depression severity measure. J Gen Intern Med. 2001;16(9):606-613.

22. Stewart A, Ware J Jr, Sherbourne C, Wells K. Psychological distress/ well-being and cognitive functioning measures. In: Stewart A, Ware J Jr, editors. Measuring Functioning and Well-being. Durham, NC: Duke University Press; 1992:67-85.

23. Yarlas A, White MK, Bjorner JB. The development and validation of a revised version of the medical outcomes study cognitive functioning scale (MOS-COG-R). Value Health. 2013;16(3):A33-A34.

24. Guy W. ECDEU Assessment Manual for Psychopharmacology-Revised (DHEW Publ No ADM 76-338). Rockville, MD: US Department of Health, Education, and Welfare, Public Health Service, Alcohol, Drug Abuse, and Mental Health Administration; 1976.

25. Sheehan DV, Harnett-Sheehan K, Raj BA. The measurement of disability. Int Clin Psychopharmacol. 1996;11(Suppl 3):89-95.

26. Sheehan DV, Harnett-Sheehan K, Spann ME, Thompson HF, Prakash A. Assessing remission in major depressive disorder and generalized anxiety disorder clinical trials with the discan metric of the Sheehan disability scale. Int Clin Psychopharmacol. 2011;26(2):75-83.

27. Reilly MC, Zbrozek AS, Dukes EM. The validity and reproducibility of a work productivity and activity impairment instrument. Pharmacoeconomics. 1993;4(5):353-365.

28. Lam RW, Michalak EE, Yatham LN. A new clinical rating scale for work absence and productivity: validation in patients with major depressive disorder. BMC Psychiatry. 2009;9:78.

29. Mchorney CA, Tarlov AR. Individual-patient monitoring in clinical practice: are available health status surveys adequate? Qual Life Res. 1995;4(4):293-307.

30. Nunnally JC, Bernstein IH. Psychometric Theory. 3rd ed. New York, NY: McGraw-Hill; 1994.

31. Clark LA, Watson D. Constructing validity: Basic issues in objective scale development. Psychol Assess. 1995;7(3):309-319.

32. Cohen J. Statistical Power Analysis for the Behavioral Sciences. 2nd ed. Hillsdale, NJ: Lawrence Erlbaum Associates; 1988

33. National Multiple Sclerosis Society. The Consortium of Multiple Sclerosis Centers Health Services Research Subcommittee. Multiple Sclerosis Quality of Life Inventory: a User's Manual. New York, NY: The National Multiple Sclerosis Society; 1997.

34. Muthén LK, Muthén BO. MPLUS User's Guide. 4th ed. Los Angeles, CA: Muthén \& Muthén; 2004.

35. Bentler PM. Comparative fit indexes in structural models. Psychol Bull. 1990;107(2):238-246.

36. Steiger JH. Structural model evaluation and modification. Multivar Behav Res. 1990;25:173-180.

37. Hu L, Bentler PM. Cutoff criteria for fit indexes in covariance structure analysis: Conventional criteria versus new alternatives. Struct Equ Modeling. 1999;6(1):1-55.

38. McDonald RP. Test Theory: A Unified Treatment. Mahwah, NJ: Lawrence Erlbaum Associates; 1999.

39. Reeve BB, Hays RD, Bjorner JB, et al; PROMIS Cooperative Group. Psychometric evaluation and calibration of health-related quality of life item banks: plans for the Patient-Reported Outcomes Measurement Information System (PROMIS). Med Care. 2007;45(5 Suppl 1):S22-S31. 
40. Fava M, Iosifescu DV, Pedrelli P, Baer L. Reliability and validity of the Massachusetts general hospital cognitive and physical functioning questionnaire. Psychother Psychosom. 2009;78(2):91-97.

41. Iverson GL, Lam RW. Rapid screening for perceived cognitive impairment in major depressive disorder. Ann Clin Psychiatry. 2013; 25(2):135-140.

42. American Psychiatric Association. Diagnostic and Statistical Manual of Mental Disorders. 4th ed. Arlington, VA: American Psychiatric Publishing; 1994.

43. Lovera J, Bagert B, Smoot KH, et al. Correlations of Perceived Deficits Questionnaire of Multiple Sclerosis Quality of Life Inventory with Beck Depression Inventory and neuropsychological tests. J Rehabil Res Dev. 2006;43(1):73-82.
44. Kim JM, Hong JP, Kim SD, Kang HJ, Lee YS. Development of a Korean version of the Perceived Deficits Questionnaire-Depression for patients with major depressive disorder. Clin Psychopharmacol Neurosci. 2016;14(1):26-32.

45. Shi C, Wang G, Tian F, et al. Reliability and validity of Chinese version of perceived deficits questionnaire for depression in patients with MDD. Psychiatry Res. 2017;252:319-324.

46. Lam RW. Subjective measures of cognitive dysfunction in depression. In: McIntyre RS, Cha D, editors. Cognitive Dysfunction in Major Depressive Disorder. Cambridge, UK: Cambridge University Press; 2016:242-256. 
Supplementary materials

Psychometric validation of the Perceived

Deficits Questionnaire-Depression

(PDQ-D) instrument in US and UK respondents with major depressive disorder

Background information on methods

Respondents/sample

The US and UK samples were provided by KnowledgePanel ${ }^{\circledR}$

(GfK Custom Research, LLC, USA) and MrOps (London,

UK), respectively. KnowledgePanel ${ }^{\circledR}$ has been in continuous use in the US since 1998 and comprises more than 50,000 adult members recruited using a combination of randomdigit-dial telephone and address-based sampling selected from the US Postal Service Computerized Delivery Sequence File. Profile information, with questions on health topics including depression, is collected and updated on an annual basis. MrOps is a specialist company with access to over 40 screened and validated sample sources worldwide, many of which are online panels.

\section{Ethics approval}

Data were collected by survey companies through their existing approved market-research panels, following their own procedures. When subjects are enrolled in such panels, they provide the panel owners with written informed consent, and agree to be contacted for participation in online surveys. For this survey, we ensured that the participants signed an additional informed consent form to participate.

In the US, this type of survey is exempt from Institutional Review Board approval according to guidelines from the US Office for Human Research Protections which stipulate that research involving the use of educational tests (cognitive, diagnostic, aptitude, achievement), survey procedures, interview procedures or observation of public behavior, are exempt unless:

1. Information obtained is recorded in such a manner that human subjects can be identified, directly or through identifiers linked to the subjects; and

2. Any disclosure of the human subjects' responses outside the research could reasonably place the subjects at risk of criminal or civil liability or be damaging to the subjects' financial standing, employability, or reputation.

For the UK, this survey does not fit any of the categories needing approval by a National Health Service Research
Ethics Committee (NHR REC) (see http://www.hra.nhs.uk/ resources/before-you-apply/is-nhs-rec-review-required/).

\section{Criterion measures}

The Patient Health Questionnaire-9 (PHQ-9) is a 9-item measure that assesses the frequency of experiencing symptoms of major depressive episode, as defined in the Diagnostic and Statistical Manual of Mental Disorders Fourth Edition, during the previous 2-week period plus one added item assessing the level of disturbance of these symptoms. ${ }^{1}$ The Medical Outcomes Study Cognitive Functioning Scale-Revised-acute form (MOS COG-R) is a 6-item instrument that measures the frequency of problems in a range of day-to-day cognitive functions, such as memory, attention, and reasoning, in the previous 1-week period. ${ }^{2,3}$ The Patient Global Impression of Severity scale (PGI-Severity) consists of a single item to assess the severity of the respondent's depression at the time of assessment. ${ }^{4}$ The 6-item Work Productivity and Activity Impairment Questionnaire: Specific-Health Problem (WPAI:SHP) measures the impact of any specific health problem (in this case, depression) on respondents' work productivity (including the duration of work time missed due to depression, as well as decreases in productivity when working while experiencing depression) and non-work related activities (eg, childcare) over the past 7 days. ${ }^{5}$ The modified Lam Employment Absence and Productivity Scale (LEAPS) is a 10-item questionnaire to assess occupational functioning and impairment over the previous 2-week period. ${ }^{6}$ The 5-item Sheehan Disability Scale (SDS) measures the degree to which mental disorder symptoms have disrupted a respondent's work/school, social, and family life in the preceding week. ${ }^{7.8}$

\section{References}

1. Kroenke K, Spitzer RL, Williams JB. The PHQ-9: validity of a brief depression severity measure. J Gen Intern Med. 2001;16(9):606-613.

2. Stewart AL, Ware JE Jr, Sherbourne CD, Wells KB. Psychological distress/well-being and cognitive functioning measures. In: Stewart AL, Ware JE Jr, editors. Measuring Functioning and Well-being: the Medical Outcomes Study Approach. Durham, NC: Duke University Press; 1992: 102142.

3. Yarlas A, White MK, Bjorner B. The development and validation of a revised version of the medical outcomes study cognitive functioning scale (MOS-COG-R). Value Health. 2013;16(3):A33-A34.

4. Guy W. ECDEU Assessment Manual for Psychopharmacology-Revised (DHEW Publ No ADM 76-338). Rockville, MD: US Department of Health, Education, and Welfare, Public Health Service, Alcohol, Drug Abuse, and Mental Health Administration; 1976.

5. Reilly MC, Zbrozek AS, Dukes EM. The validity and reproducibility of a work productivity and activity impairment instrument. Pharmacoeconomics. 1993;4(5):353-365. 
6. Lam RW, Michalak EE, Yatham LN. A new clinical rating scale for work absence and productivity: validation in patients with major depressive disorder. BMC Psychiatry. 2009;9:78.

7. Sheehan DV, Harnett-Sheehan K, Raj BA. The measurement of disability. Int Clin Psychopharmacol. 1996;11(Suppl 3):89-95.
8. Sheehan DV, Harnett-Sheehan K, Spann ME, Thompson HF, Prakash A. Assessing remission in major depressive disorder and generalized anxiety disorder clinical trials with the discan metric of the Sheehan disability scale. Int Clin Psychopharmacol. 2011;26(2):75-83.

\section{Publish your work in this journal}

Neuropsychiatric Disease and Treatment is an international, peerreviewed journal of clinical therapeutics and pharmacology focusing on concise rapid reporting of clinical or pre-clinical studies on a range of neuropsychiatric and neurological disorders. This journal is indexed on PubMed Central, the 'PsycINFO' database and CAS, and is the official journal of The International Neuropsychiatric Association (INA). The manuscript management system is completely online and includes a very quick and fair peer-review system, which is all easy to use. Visit http://www.dovepress.com/testimonials.php to read real quotes from published authors.

\footnotetext{
Submit your manuscript here: http://www.dovepress.com/neuropsychiatric-disease-and-treatment-journal
} 